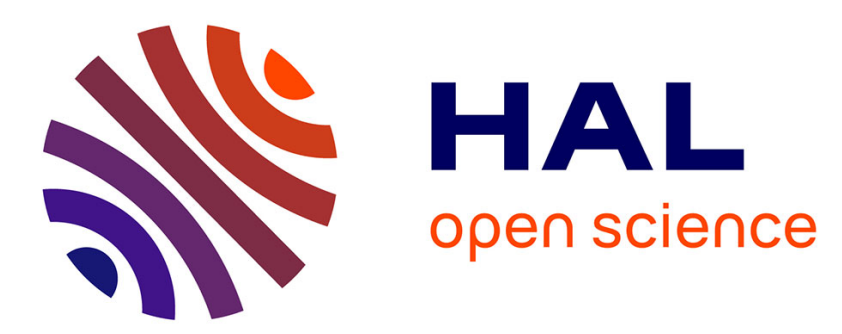

\title{
Filial egg cannibalism in the European earwig: its determinants and implications in the evolution of maternal egg care
}

Sophie van Meyel, Joël Meunier

\section{- To cite this version:}

Sophie van Meyel, Joël Meunier. Filial egg cannibalism in the European earwig: its determinants and implications in the evolution of maternal egg care. Animal Behaviour, 2020, 164, pp.155-162. 10.1016/j.anbehav.2020.04.001 . hal-02613358

\section{HAL Id: hal-02613358 \\ https://hal-univ-tours.archives-ouvertes.fr/hal-02613358}

Submitted on 20 May 2020

HAL is a multi-disciplinary open access archive for the deposit and dissemination of scientific research documents, whether they are published or not. The documents may come from teaching and research institutions in France or abroad, or from public or private research centers.
L'archive ouverte pluridisciplinaire HAL, est destinée au dépôt et à la diffusion de documents scientifiques de niveau recherche, publiés ou non, émanant des établissements d'enseignement et de recherche français ou étrangers, des laboratoires publics ou privés. 


\section{Filial egg cannibalism in the European earwig: its determinants and implications in the evolution of maternal egg care}

Sophie Van Meyel*, Joël Meunier

Institut de Recherche sur la Biologie de l'Insecte, UMR 7261 CNRS - Université de Tours, Tours, France

*Correspondence: S. Van Meyel, Institut de Recherche sur la Biologie de l'Insecte, UMR 7261 CNRS - Université de Tours, : Parc de Grandmont, 37200 Tours, France.

E-mail address: sophie.vanmeyel@univ-tours.fr 


\section{ABSTRACT}

In many animal species, mothers eat some of their own eggs. While this filial egg cannibalism can have profound impacts on both parental and offspring fitness, it remains unclear whether this behaviour is a simple by-product of a generally low maternal investment in egg care and whether it is determined before or after egg production. Here, we addressed these questions in the European earwig, Forficula auricularia, an insect in which females vary in their level of investment in egg care and in their expression of egg cannibalism. Using a cross-fostering experiment, we investigated the benefits of egg cannibalism for mothers, the potential association between egg cannibalism and egg care, and whether egg cannibalism is a maternal strategy that is determined before or after egg laying. Our results first revealed that egg cannibalism provided direct benefits to mothers, as the females that consumed some of their eggs increased their investment in future reproduction. We then showed that egg cannibalism was independent of the level of maternal investment in two important forms of egg care (egg defence and the time taken to return after a simulated predator attack). This overall suggests that access to egg cannibalism may select for mothers to remain with their eggs, independent of the potential benefits of care for the eggs. Finally, we demonstrated that the number of eggs received, but not the number of eggs produced by foster mothers, determined the level of egg cannibalism. This highlights that egg cannibalism is determined after egg laying and is not the outcome of anticipatory maternal effects. Overall, these findings provide novel insights into our understanding of the early evolution of parental care, as they suggest that the direct benefits of filial egg cannibalism for mothers could have promoted egg attendance from an ancestral egg abandonment state.

Keywords: Dermaptera, infanticide, maternal care, parental care. 


\section{INTRODUCTION}

Parents can employ multiple strategies to maximize their own and/or their descendants' fitness after egg production (Smiseth, Kölliker, \& Royle, 2012). Most of these strategies are energetically costly for parents and consist of providing care to protect their eggs against predators, pathogens and harsh environmental conditions (Clutton-Brock, 1991; Royle, Smiseth, \& Kölliker, 2012). However, parents of several animal species (Elgar \& Crespi, 1992) adopt strategies that are energetically beneficial for them and costly for some of their eggs, such as reducing the clutch size through egg consumption (Klug \& Bonsall, 2007; Manica, 2002). This so-called partial filial egg cannibalism is often viewed as an adaptive strategy because it can provide some benefits to mothers. For instance, egg consumption can allow mothers to limit the level of posthatching sibling competition and to remove unviable and infected eggs that could otherwise favour the spread of microbial pathogens to the rest of the clutch (Bartlett, 1987; Creighton, 2005). Similarly, filial egg cannibalism may allow females to reallocate resources to future reproduction and/or a higher quality of care to current clutches (Rohwer, 2002; Sargent, 1992).

While partial filial egg cannibalism has a profound impact on both parental and offspring fitness (Klug \& Bonsall, 2007; Manica, 2002), the link between this behaviour and the general parental investment in egg care, as well as the proximate drivers of this behaviour, remains unclear. Demonstrating that egg cannibalism and egg care are independent would first suggest that egg cannibalism is not a simple by-product of a low or high investment of mothers in care. This would indicate that the sole benefits of egg cannibalism (for instance in terms of future reproduction) could select for mothers to remain with their eggs when these do not require care to survive, a scenario that probably prevailed in the early evolution of egg brooding (Furness \& Capellini, 2019; Royle et al., 2012). Moreover, demonstrating that partial filial egg cannibalism is a maternal 
strategy that is determined before and/or after egg laying may provide key information on the selection pressures operating on the evolution of egg cannibalism and on how this phenomenon can ultimately (and somewhat counterintuitively) improve maternal fitness. In particular, a strategy determined before egg laying may allow mothers to account for future access to food resources (i.e. eggs) during times where either egg care or other reproductive or seasonal limitations prohibit foraging. This strategy could operate, for instance, in species where females are under a physiological constraint enforcing the development of (even unfertilized) eggs in their reproductive tract, a phenomenon found in numerous species such as the terrestrial isopod Armadillidium pelagicum (Hamaied, Nasri-Ammar, \& Charfi-Cheikhrouha, 2004), the fruit fly Drosophila mangabeirai (Murdy \& Carson, 1959) and the European earwig, Forficula auricularia (S. Van Meyel \& J. Meunier, personal observation). On the other hand, a strategy determined after egg laying could allow parents to optimize their energetic resources in unpredictable environments (Rohwer, 2002; Sargent, 1992) and should thus reflect a process not primarily determined by the maternal genetic background and/or by anticipatory maternal effects.

In this study, we investigated whether filial egg cannibalism (1) provides benefits to mothers in the European earwig, (2) depends on the level of maternal investment in egg care and (3) is determined before and/or after egg production. In this insect species, females produce up to two clutches in their lifetime without remating (Meunier et al., 2012; Ratz, Kramer, Veuille, \& Meunier, 2016; Tourneur \& Meunier, 2020). Earwig mothers typically tend their first clutch of eggs for several weeks in winter (Kölliker, 2007; Lamb, 1976), during which they stop foraging and provide multiple forms of care (Boos, Meunier, Pichon, \& Kölliker, 2014; Diehl \& Meunier, 2018; Kölliker, 2007). Hence, during the period of egg care, earwig females have no food source other than their own eggs. Recent studies have shown that earwig females can consume some of 
their eggs during this period (Koch \& Meunier, 2014) and that mothers with large clutches are more likely to express this behaviour than those with small clutches (Koch \& Meunier, 2014). The underlying drivers of this link, however, are unknown.

Here, we cross-fostered clutches of different sizes and then measured the occurrence and level of filial egg cannibalism by the foster mothers (based on their weight gain), as well as their investment in egg care and second-clutch production. If egg consumption benefits mothers, we predicted that a second clutch would be both more likely to be produced and larger in cannibal than noncannibal mothers, i.e. in females that gained weight compared to those that lost weight during the period of egg care. If filial egg cannibalism is independent of egg care, we predicted no association between the level of egg care expressed by a female and its weight gain during this period. Finally, if filial egg cannibalism is determined before (or after) egg laying, we predicted that the number of eggs produced (or the number received) by a foster mother would drive the known positive association between clutch size and likelihood of egg cannibalism (Koch \& Meunier, 2014; Miller \& Zink, 2012).

\section{METHODS}

\section{Experimental design and measurements}

The 74 earwig females used in this study were collected in June 2017 at Pont-de-Ruan (France) and were then maintained under standard laboratory conditions until egg laying (Meunier et al., 2012). Because females need up to 3 days to produce their full clutch of eggs (Koch \& Meunier, 2014), we counted the eggs produced by each female 3 days after egg laying. One day later, we randomly exchanged the full clutch of each mother with the first clutch of another, unrelated mother. This cross-fostering was possible because earwig mothers do not discriminate against 
foreign eggs (Van Meyel, Devers, \& Meunier, 2019). Overall, this process led to 74 experimental families in which each mother originally produced from 12 to 53 eggs and then received a clutch that was from $70 \%$ smaller to $95 \%$ larger than its original clutch (see distribution in Appendix Fig. A1). There was no association between the number of eggs produced and those received by the foster mothers (Spearman correlation: rho $=-0.102, S=74388, P=0.389$ ). These experimental families were then maintained at $10{ }^{\circ} \mathrm{C}$ in constant darkness to mimic winter conditions and allow egg development (Meunier et al., 2012). They were not given any food source between egg production and egg hatching, as females typically stop foraging during this period (Kölliker, 2007).

Five days after the cross-fostering, we used standard protocols to measure maternal investment in two important forms of egg care (Diehl \& Meunier, 2018; Thesing, Kramer, Koch, \& Meunier, 2015; Van Meyel et al., 2019). We first measured clutch defence, which reflects females' willingness to protect their eggs from predator attacks, by standardly poking females on the pronotum with a glass capillary and then recording the number of pokes required until they moved more than 1 body length away from the clutch. High values of clutch defence (poke number) therefore show high maternal investment in egg care and vice versa. We then measured the delay after which females returned to their clutch after being chased away by a simulated predator attack (henceforth, 'delay of maternal return') by recording the time it took each female to return to its clutch after the end of the clutch defence measurement. Long delays of maternal return indicate low maternal investment in egg care and vice versa. Overall, females showing high levels of clutch defence tended to have shorter delays of maternal return, but this was not significant (Spearman correlation test: $\mathrm{rho}=-0.222, S=76012, P=0.061$ ).

One day after egg hatching, families were transferred to standard summer conditions (Meunier et al., 2012) and received an ad libitum amount of standard food twice a week (see 
detailed food composition in Meunier et al., 2012). Fourteen days later, juveniles were removed from their mothers to mimic natural family dispersion (Lamb, 1975; Meunier et al., 2012), while mothers were maintained in constant darkness to allow second-clutch production (Meunier et al., 2012). When these mothers produced a second clutch, we counted the eggs 3 days after egg laying.

The occurrence and levels of filial egg cannibalism were measured using two proxies based on female weight gain. We used female weight gain instead of simply counting the eggs that did not hatch, because multiple factors independent of filial egg cannibalism can shape hatching success in earwigs. For instance, failures in egg developmental processes result in eggs that either dry out and disappear (the most frequent) or remain unhatched, and clutches suffer from recurrent egg cannibalism by newly hatched siblings (Koch \& Meunier, 2014; Miller \& Zink, 2012). Our first proxy of egg cannibalism was the absolute weight gained by mothers between egg laying and egg hatching. This proxy provides quantitative information on egg consumption (continuous variable), as earwig mothers do not have access to any food source between egg laying and hatching and thus the absolute weight gained by a mother during this period necessarily (and at least partly) reflects the number of eggs it eats (Koch \& Meunier, 2014; Miller \& Zink, 2012). The limit of this proxy, however, is that maternal idiosyncrasies may also affect female weight during this period and could thus blur our quantitative interpretation of egg cannibalism. To confirm that this limit does not alter the robustness of our conclusions, we also used a qualitative proxy of egg cannibalism (categorical variable). This proxy defined 'cannibal mothers' as the females that gained weight between egg laying and egg hatching ( $N=19$ mothers; see Results) and 'noncannibal mothers' as the females that lost weight during this period $(N=55)$. The benefit of this second proxy is that 'cannibal mothers' may only include females that ate eggs, whereas its limit is that 'noncannibal mothers' may also include a few females that did consume a small part 
of their clutch (but the weight gained through this consumption was lower than the weight lost for other reasons). Given the complementarity of these two proxies, we believe that their combined use comprehensively and conservatively characterizes filial egg cannibalism and thus allowed us to explore its costs and benefits, as well as its determinants in earwigs. Female weight gain during the period of egg care was calculated by subtracting the mother's fresh weight measured 3 days after egg laying from the mother's fresh weight measured 1 day after egg hatching. All weights were measured to the nearest $0.01 \mathrm{mg}$ using a microbalance (OHAUS Discovery DV215CD)

\section{Statistical analyses}

The potential costs and benefits of egg cannibalism for mothers were analysed using a series of two generalized linear models (GLM) fitted with binomial error distributions, and three general linear models (LM). In these models, the response variable was either the hatching success (GLM), the likelihood of producing a second clutch (GLM), the number of second-clutch eggs produced (LM), the level of clutch defence (LM) or the delay of maternal return (LM). All these models included three explanatory variables, which were the weight gained by foster mothers during the period of egg care (our quantitative proxy of filial egg cannibalism), the number of eggs they produced in their first clutch and the interaction between these two factors. These models finally included one covariable, the weight of the foster mothers at egg production, which was used to account for female body condition in the potential costs and benefits of egg cannibalism. To confirm that our results did not depend on the selected proxy of filial egg cannibalism (and its associated limits), we then reran the exact same series of five statistical models but used cannibal/noncannibal mothers as a categorical explanatory variable instead of the weight gained by foster mothers. 
We then tested whether filial egg cannibalism depends on the number of eggs produced and/or received by the females using two statistical models, in which the response variable was either the quantitative proxy (i.e. female absolute weight gain, LM) or the qualitative proxy (i.e. cannibal versus noncannibal mothers, GLM) of filial egg cannibalism. In these models, the explanatory variables were the number of first-clutch eggs produced by the foster females, the number of first-clutch eggs they received and the interaction between these two variables. Note that a significant interaction between these two factors would suggest that filial egg cannibalism depends on whether mothers received more or fewer eggs than they had laid. In these models, we also entered the weight of foster mothers at egg production as a covariable.

All these models were conducted with the software R v3.6.0 (R Core Team, 2017). Each model was checked for homoscedasticity and normality of residuals and, when required, variables were transformed to fulfil model assumptions. In particular, the weights gained by mothers during the period of egg care were log+0.01 transformed, the level of clutch defence was log transformed and the delay of maternal return was $\log +1$ transformed. These transformations were also used in the figures. When applicable, the hatching success was entered through the cbind function in $\mathrm{R}$, in which we used the number of nymphs at hatching on the one hand, and the difference between the number of eggs received and the number of newly hatched nymphs on the other.

\section{Ethical Note}

We used a total of 74 individuals in this study. No animal ethics approval was required. All individuals were handled with care.

\section{RESULTS}


Overall, variation in female weight during the period of egg care ranged from a loss of $7.84 \mathrm{mg}$ (13.5\% of its initial weight) to a gain of $22.14 \mathrm{mg}$ ( $48.6 \%$ of its initial weight), with a total of 19 (24.7\%) females that gained weight and were thus the most likely to have performed filial egg consumption (hereafter called 'cannibal mothers' in contrast to the 55 'noncannibal mothers'). Among the 74 tested females, 53 (71.6\%) produced a second clutch, which contained 5 - 43 eggs $($ mean $\pm \mathrm{SE}=22.42 \pm 1.38)$.

Female weight gain between egg production and egg hatching (our quantitative proxy of filial egg cannibalism) was overall negatively correlated with egg hatching success (model estimate $\pm \mathrm{SE}=-18.90 \pm 3.88$; Table 1, Fig. 1a). By contrast, it was positively correlated with both the likelihood of producing a second clutch (model estimate $\pm \mathrm{SE}=1.47 \pm 0.67$; Table 1, Fig. 1b) and, when present, with the number of second-clutch eggs they produced (model estimate $\pm \mathrm{SE}=$ $7.37 \pm 2.14$; Table 1, Fig. 1c). The use of the qualitative proxy of egg cannibalism provided the same results. Cannibal mothers had a lower egg hatching success (Table 1, Fig. 1d), but a higher likelihood of producing a second clutch (Table 1, Fig. 1e) and a larger number of second-clutch eggs (Table 1, Fig. 1f) compared to noncannibal mothers. Note that the negative associations between egg hatching success and filial egg cannibalism (found with both proxies, Fig. 1a, d) remain significant when females with a hatching success of zero are removed from the data sets (Table A1). Independent of the level of filial egg cannibalism and of the proxy we used, the egg hatching success was negatively correlated with the weight of females at egg laying (model estimate $\pm \mathrm{SE}=-85.01 \pm 31.95 ;$ Table 1$)$.

The range in level of clutch defence expressed by the tested mothers was $2-100$ pokes (Fig. 2a; mean $\pm \mathrm{SE}=21.14 \pm 2.06$ ), while that in the delay of maternal return was $0-1200 \mathrm{~s}$ (Fig. $2 \mathrm{~b}$; mean $\pm \mathrm{SE}=121.9 \pm 32.3$ ). These two forms of maternal care were independent of filial egg 
cannibalism (with both quantitative and qualitative proxies; Table 1, Fig. 2a, b, c, d), as well as of their initial body weight and production of first-clutch eggs (Table 1).

Female weight gain was positively associated with the number of eggs they received ( $F_{1,69}$ $=6.77, P=0.011$; Fig. 3a). However, it was independent of the number of eggs they produced $\left(F_{1,69}=1.29, P=0.259\right.$; Fig. $\left.3 b\right)$, the interaction between the number of eggs they received and produced $\left(F_{1,69}=0.10, P=0.752\right)$ and their initial weight at egg laying $\left(F_{1,69}=0.83, P=0.367\right)$. The use of the qualitative proxy of egg cannibalism provided comparable results: females defined as 'cannibal mothers' received more eggs than noncannibal females $\left(\mathrm{LR}_{1}=4.55, P=0.033\right.$; Fig. $3 c)$, whereas they produced the same number of eggs $\left(\operatorname{LR}_{1}=0.15, P=0.703\right.$; Fig. $\left.3 \mathrm{~d}\right)$ and showed no difference in initial body weight $\left(\mathrm{LR}_{1}<0.01, P=0.982\right)$.

\section{DISCUSSION}

Shedding light on the nature and determinants of filial egg cannibalism is of central importance to better understand how and why this surprising phenomenon has emerged in nature and to reveal its potential link to the evolution of parental care. Using a cross-fostering experiment in the European earwig, we demonstrated that filial egg consumption, measured through maternal weight

gain, was (1) associated with an increase in maternal investment in future egg production, (2) independent of how much mothers invested in two classic forms of egg care and (3) determined by the number of eggs tended, and not by the eggs produced, by the mother. Interestingly, our results also showed a negative association between egg hatching success and female body weight at egg laying, and confirmed both the absence of a trade-off between first- and second-clutch production in this species and the coexistence of females exhibiting either high or low overall investment in egg production (Meunier et al., 2012; Ratz et al., 2016). 
We first found that filial egg cannibalism was positively associated with both the likelihood of producing and the size of a second (terminal) clutch. These associations suggest that mothers expressing egg cannibalism have either a better intrinsic quality than mothers that do not or that egg consumption allows mothers to increase their investment in future reproduction. The first hypothesis is unlikely to explain our results, as we showed that female weight at egg laying did not differ between mothers that did or did not eat eggs. Conversely, the second hypothesis is in line with results from studies conducted in other animal species (Klug \& Bonsall, 2007; Manica, 2002). These results show that egg cannibalism can allow parents to reallocate resources from a current reproductive effort to a future one when current environmental conditions become harsh and render their present eggs unlikely to develop and survive (Manica, 2002; Sargent, 1992). In our experiment, however, earwig mothers experienced neither harsh nor changing environments, so that the benefits of reallocating resources from current to future reproduction were low (if any) and thus unlikely to be the main driver of this phenomenon. One hypothesis to explain why earwig mothers consumed some of their eggs is that clutch size reduction limits the risks of competition between future juveniles (Mock \& Parker, 1998) and that its associated direct benefits for mothers (increasing nutrient intake) are simple by-products. In line with this explanation, previous studies reported that earwig family life is shaped by fierce competitive interactions between siblings (Dobler \& Kölliker, 2010, 2011) and that mothers reduce the number of newly hatched juveniles under specific conditions (Kramer et al., 2017; Kramer \& Meunier, 2016; Kramer, Thesing, \& Meunier, 2015). The high likelihood of egg cannibalism when clutches are large (data in the present study; Koch \& Meunier, 2014) could thus reflect an efficient maternal strategy to limit the subsequent level of sibling competition, as reported in the burying beetle, Nicrophorus tomentosus 
(Trumbo, 1990). Further work exploring the costs and benefits of egg cannibalism for offspring fitness is nevertheless required to confirm this hypothesis.

The fact that cannibal mothers were more likely both to produce a second clutch and to produce more second-clutch eggs does not necessarily imply that they had a higher fitness due to a larger net productivity (i.e. total number of uneaten eggs produced) or to producing better-quality offspring. Given that the two types of mothers produced a comparable number of first-clutch eggs, the net productivity of cannibal mothers can be larger than that of noncannibal mothers only if their production of second-clutch eggs outweighs their consumption of first-clutch eggs. Our results, however, show that the 19 females classified as 'cannibal mothers' produced $25.78 \pm 2.17$ second-clutch eggs, whereas $36.21 \pm 2.79$ of their first-clutch eggs did not hatch (Welch $t$ test: $\left.t_{33.48}=2.96, P=0.006\right)$. Even if the number of unhatched eggs does not include cannibalized eggs (see Methods), these values suggest that cannibal mothers produced only as many, or fewer, second-clutch eggs as the number of first-clutch eggs they ate, and thus that their net productivity was comparable to or lower than that of noncannibal ones. Similarly, previous studies showed that the quality of earwig juveniles (estimated from their weight, developmental speed and survival rate) is comparable between first and second clutches (Meunier et al., 2012; Ratz et al., 2016; Tourneur \& Meunier, 2020), suggesting that a preferential investment in the production of one of these two clutches does not necessarily reflect a preferential investment in high- or low-quality offspring. Overall, the absence of a clear fitness benefit of filial egg cannibalism for mothers in terms of net productivity and/or high-quality offspring may explain why few mothers perform this behaviour in the European earwig (see also Koch \& Meunier, 2014).

Our results also demonstrate that earwigs' filial egg cannibalism was independent of two important forms of maternal egg care: clutch defence and the delay of maternal return. The level 
of maternal investment in egg care can show broad interindividual variation in nature, which often leads to important variation in the development and survival of the resulting eggs and offspring (Van Dijk et al., 2012; Westneat, Hatch, Wetzel, \& Ensminger, 2011; Williams \& Fowler, 2015). This link is known in the European earwig, where females' investment in both pre- and posthatching care varies greatly, which has major consequences for offspring in terms of, for instance, egg development time or weight at hatching (Boos et al., 2014; Kölliker, 2007; Kölliker \& Vancassel, 2007; Van Meyel et al., 2019). Here, we have shown that low maternal investment in egg care does not necessarily come with high levels of egg cannibalism (and vice versa). This reveals that egg cannibalism is not on a continuum from poor to high maternal investment in egg care and instead reflects a specific phenomenon that could evolve under different selection pressures than those driving the evolution of egg care. This opens the scope for future research exploring these selection pressures and studying their roles in the early emergence of brood care from the ancestral nonbrood care state (Furness \& Capellini, 2019; Wong, Meunier, \& Kölliker, 2013).

The use of a cross-fostering experimental design finally allowed us to demonstrate that the known positive link between clutch size and filial egg cannibalism (Koch \& Meunier, 2014) is driven by the number of eggs that are tended by the mothers and not by the number of eggs they have laid or by differences between the number of eggs laid and received. An effect of the number of eggs produced could have been expected in species in which females both incur physiological constraints forcing them to lay their eggs and experience long and planned periods of starvation, two parameters present in the European earwig (Lamb, 1976). Assuming that the resulting costs of egg production would be very limited in these species compared to the benefits of ensuring access to future food resources, these mothers would benefit directly from producing a number of 
eggs tightly associated with their future needs. Our results, however, do not support this scenario in earwigs. Instead, they suggest that the costs of egg production are typically larger than the benefits of egg consumption and thus that egg cannibalism is a behaviour determined after egg laying.

On a more general level, our findings highlight that the presence of egg care can be entangled with the presence of other behaviours that directly or indirectly improve maternal investment in future reproduction at the cost of (some) current egg survival. The benefits of egg cannibalism for mothers could be important regarding the evolution of egg brooding from a nonegg-brooding state, because access to partial egg cannibalism may (at least partly) select for mothers to remain with their eggs (i.e. egg brooding). Enhancing egg development and survival may thus not be the sole evolutionary drivers of the emergence and consolidation of egg brooding. This alternative (but non-mutually exclusive) evolutionary scenario could be particularly well suited for species in which mothers have long life spans and limited access to food after egg laying, as in the European earwig in which females live for 1.5 years and stop their foraging activities during the period of egg care (Kölliker, 2007; Lamb, 1976; Tourneur \& Meunier, 2020). Moreover, the cost of maternal presence for the survival of some eggs reported in this study is in line with that for some earwig juveniles (when food resources are limited) reported in previous studies (Kramer et al., 2017; Meunier \& Kölliker, 2012). Altogether, these results demonstrate that the presence of a mother with its descendants (eggs or juveniles) is not necessarily associated with net benefits for the latter (although the benefits of egg cannibalism for the surviving offspring have yet to be explored), which questions the central roles of parental care and its benefits for offspring in current theories on the early evolution of family life (Kramer et al., 2017; Kramer \& Meunier, 2018; Meunier \& Kölliker, 2012). 


\section{Data Availability}

Analyses reported in this manuscript can be reproduced using the data available in the free repository server Zenodo (Van Meyel \& Meunier, 2020).

\section{ACKNOWLEDGMENTS}

We thank Florent Figon, Maximilian Körner, Anthony Mathiron, Fanny Ruhland, Lucas Sire, Jean-Claude Tourneur and two anonymous reviewers for their insightful comments on the manuscript and Severine Devers for technical support. We also thank Laurent Ardouin for providing access to his orchards for earwig field sampling. This research has been supported by a research grant from the French Ministry of Higher Education and Research.

\section{REFERENCES}

Bartlett, J. (1987). Filial cannibalism in burying beetles. Behavioral Ecology and Sociobiology, 21(3), 179-183. https://doi.org/10.1007/BF00303208

Boos, S., Meunier, J., Pichon, S., \& Kölliker, M. (2014). Maternal care provides antifungal protection to eggs in the European earwig. Behavioral Ecology, 25(4), 754-761. https://doi.org/10.1093/beheco/aru046

Clutton-Brock, T. H. (1991). The evolution of parental care. Princeton, NJ: Princeton University Press.

Creighton, J. C. (2005). Population density, body size, and phenotypic plasticity of brood size in a burying beetle. Behavioral Ecology, 16(6), 1031-1036. https://doi.org/10.1093/beheco/ari084 
Diehl, J. M. C., \& Meunier, J. (2018). Surrounding pathogens shape maternal egg care but not egg production in the European earwig. Behavioral Ecology, 29(1), 128-136. https://doi.org/10.1093/beheco/arx140

Dobler, R., \& Kölliker, M. (2010). Kin-selected siblicide and cannibalism in the European earwig. Behavioral Ecology, 21(2), 257-263. https://doi.org/10.1093/beheco/arp184

Dobler, R., \& Kölliker, M. (2011). Influence of weight asymmetry and kinship on siblicidal and cannibalistic behaviour in earwigs. Animal Behaviour, 82(4), 667-672. https://doi.org/10.1016/J.ANBEHAV.2011.06.017

Elgar, M. A., \& Crespi, B. J. (1992). Cannibalism: ecology and evolution among diverse taxa. Oxford, U.K.: Oxford University Press.

Furness, A. I., \& Capellini, I. (2019). The evolution of parental care diversity in amphibians. Nature Communications, 10(1), 4709. https://doi.org/10.1038/s41467-019-12608-5

Hamaied, S., Nasri-Ammar, K., \& Charfi-Cheikhrouha, F. (2004). Reproductive phenology of a natural population of Armadillidium pelagicum Arcangeli, 1955 (Isopoda, Oniscidea). Comptes Rendus - Biologies, 327(4), 335-342. https://doi.org/10.1016/j.crvi.2004.02.003

Klug, H., \& Bonsall, M. B. (2007). When to care for, abandon, or eat your offspring: the evolution of parental care and filial cannibalism. The American Naturalist, 170(6), 886901. https://doi.org/10.1086/522936

Koch, L., \& Meunier, J. (2014). Mother and offspring fitness in an insect with maternal care: phenotypic trade-offs between egg number, egg mass and egg care. BMC Evolutionary Biology, 14(1), 125. https://doi.org/10.1186/1471-2148-14-125

Kölliker, M. (2007). Benefits and costs of earwig (Forficula auricularia) family life. Behavioral Ecology and Sociobiology, 61(9), 1489-1497. https://doi.org/10.1007/s00265-007-0381-7 
Kölliker, M., \& Vancassel, M. (2007). Maternal attendance and the maintenance of family groups in common earwigs (Forficula auricularia): A field experiment. Ecological Entomology, 32(1), 24-27. https://doi.org/10.1111/j.1365-2311.2006.00831.x

Kramer, J., Körner, M., Diehl, J. M. C., Scheiner, C., Yüksel-Dadak, A., Christl, T., ... Meunier, J. (2017). When earwig mothers do not care to share: Parent-offspring competition and the evolution of family life. Functional Ecology, 31(11), 2098-2107. https://doi.org/10.1111/1365-2435.12915

Kramer, J., \& Meunier, J. (2016). Maternal condition determines offspring behavior toward family members in the European earwig. Behavioral Ecology, 27(2), 494-500. https://doi.org/10.1093/beheco/arv181

Kramer, J., \& Meunier, J. (2018). The other facets of family life and their role in the evolution of animal sociality. Biological Reviews. https://doi.org/10.1111/brv.12443

Kramer, J., Thesing, J., \& Meunier, J. (2015). Negative association between parental care and sibling cooperation in earwigs: a new perspective on the early evolution of family life? Journal of Evolutionary Biology, 28(7), 1299-1308. https://doi.org/10.1111/jeb.12655

Lamb, R. J. (1975). Effects of dispersion, travel, and environmental heterogeneity on populations of the earwig Forficula auricularia L. Canadian Journal of Zoology, 53(12), 1855-1867. https://doi.org/10.1139/z75-219

Lamb, R. J. (1976). Parental behavior in the Dermaptera with special reference to Forficula auricularia (Dermaptera: Forficulidae). The Canadian Entomologist, 108(06), 609-619. https://doi.org/10.4039/ent108609-6

Manica, A. (2002). Filial cannibalism in teleost fish. Biological Reviews, 77(2), 261-277. https://doi.org/10.1017/S1464793101005905 
Meunier, J., \& Kölliker, M. (2012). When it is costly to have a caring mother: food limitation erases the benefits of parental care in earwigs. Biology Letters, 8(4), 547-550. https://doi.org/10.1098/rsbl.2012.0151

Meunier, J., Wong, J. W. Y., Gómez, Y., Kuttler, S., Röllin, L., Stucki, D., \& Kölliker, M. (2012). One clutch or two clutches? Fitness correlates of coexisting alternative female lifehistories in the European earwig. Evolutionary Ecology, 26(3), 669-682. https://doi.org/10.1007/s10682-011-9510-x

Miller, J. S., \& Zink, A. G. (2012). Parental care trade-offs and the role of filial cannibalism in the maritime earwig, Anisolabis maritima. Animal Behaviour, 83(6), 1387-1394. https://doi.org/10.1016/j.anbehav.2012.03.006

Mock, D. W., \& Parker, G. A. (1998). The evolution of sibling rivalry. New York, NY: Oxford University Press.

Murdy, W. H., \& Carson, H. L. (1959). Parthenogenesis in Drosophila mangabeirai Malog. The American Naturalist, 93(873), 355-363. https://doi.org/10.1086/282095

R Core Team. (2017). R: A Language and Environment for Statistical Computing. Vienna, Austria: R Foundation for Statistical Computing. Retrieved from http://www.r-project.org/ Ratz, T., Kramer, J., Veuille, M., \& Meunier, J. (2016). The population determines whether and how life-history traits vary between reproductive events in an insect with maternal care. Oecologia, 182(2), 443-452. https://doi.org/10.1007/s00442-016-3685-3

Rohwer, S. (2002). Parent cannibalism of offspring and egg raiding as a courtship strategy. The American Naturalist, 112(984), 429-440. https://doi.org/10.1086/283284

Royle, N. J., Smiseth, P. T., \& Kölliker, M. (2012). The evolution of parental care. Oxford, U.K.: Oxford University Press. 
Sargent, R. C. (1992). Ecology of filial cannibalism in fish. In: Cannibalism: ecology and evolution among diverse taxa. (Ed. by M. A. Elgar \& B. J. Crespi) (pp. 38-62). Oxford, U.K.: Oxford University Press.

Smiseth, P. T., Kölliker, M., \& Royle, N. J. (2012). What is parental care? In: The evolution of parental care. (Ed. by N. J. Royle, P. T. Smiseth and M. Kölliker). (pp. 1-17). Oxford, U.K.: Oxford University Press.

Thesing, J., Kramer, J., Koch, L. K., \& Meunier, J. (2015). Short-term benefits, but transgenerational costs of maternal loss in an insect with facultative maternal care. Proceedings of the Royal Society of London B: Biological Sciences, 282(1817), 20151617. https://doi.org/10.1098/rspb.2015.1617

Tourneur, J., \& Meunier, J. (2020). Variations in seasonal (not mean) temperatures drive rapid adaptations to novel environments at a continent-scale. Ecology. https://doi.org/10.1002/ecy.2973

Trumbo, S. T. (1990). Regulation of brood size in a burying beetle, Nicrophorus tomentosus (Silphidae). Journal of Insect Behavior, 3(4), 491-500. https://doi.org/10.1007/BF01052013

Van Dijk, R. E., Székely, T., Komdeur, J., Pogány, Á., Fawcett, T. W., \& Weissing, F. J. (2012). Individual variation and the resolution of conflict over parental care in penduline tits. Proceedings of the Royal Society B: Biological Sciences, 279(1735), 1927-1936. https://doi.org/10.1098/rspb.2011.2297

Van Meyel, S., \& Meunier J. (2020). Filial egg cannibalism in the European earwig: its determinants and implications in the evolution of maternal egg care [Data set]. Zenodo. http://doi.org/10.5281/zenodo.3678621

Van Meyel, S., Devers, S., \& Meunier, J. (2019). Love them all: Mothers provide care to foreign 
eggs in the European earwig Forficula auricularia. Behavioral Ecology, 30(3), 756-762. https://doi.org/10.1093/beheco/arz012

Westneat, D. F., Hatch, M. I., Wetzel, D. P., \& Ensminger, A. L. (2011). Individual Variation in Parental Care Reaction Norms: Integration of Personality and Plasticity. The American Naturalist, 178(5), 652-667. https://doi.org/10.1086/662173

Williams, T. D., \& Fowler, M. A. (2015). Individual variation in workload during parental care: can we detect a physiological signature of quality or cost of reproduction? Journal of Ornithology, 156(S1), 441-451. https://doi.org/10.1007/s10336-015-1213-6

Wong, J. W. Y., Meunier, J., \& Kölliker, M. (2013). The evolution of parental care in insects: the roles of ecology, life history and the social environment. Ecological Entomology, 38(2), 123-137. https://doi.org/10.1111/een.12000

Appendix- (Fig. A1, Table A1) 
Table 1. Effects of female body mass at egg laying, egg cannibalism and egg production on hatching success, likelihood of female producing a second clutch, the number of second-clutch eggs, clutch defence and delay of maternal return after predator attack

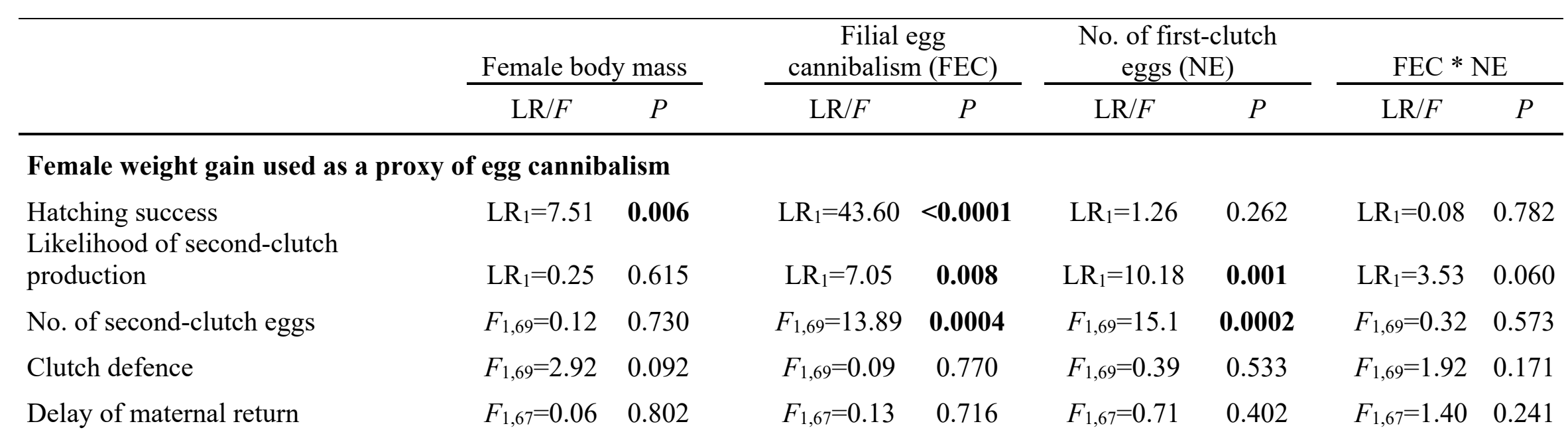

\section{Category of female cannibalism used as a proxy of egg cannibalism}

\begin{tabular}{lccccccccc}
$\begin{array}{l}\text { Hatching success } \\
\text { Likelihood of second-clutch } \\
\text { production }\end{array}$ & $\mathrm{LR}_{1}=4.64$ & $\mathbf{0 . 0 3 1}$ & $\mathrm{LR}_{1}=37.19$ & $<\mathbf{0 . 0 0 0 1}$ & $\mathrm{LR}_{1}=3.08$ & 0.079 & $\mathrm{LR}_{1}=0.04$ & 0.844 \\
No. of second-clutch eggs & $\mathrm{LR}_{1}=0.01$ & 0.936 & $\mathrm{LR}_{1}=11.58$ & $\mathbf{0 . 0 0 1}$ & $\mathrm{LR}_{1}=14.58$ & $\mathbf{0 . 0 0 0 1}$ & $\mathrm{LR}_{1}=1.64$ & 0.200 \\
Clutch defence & $F_{1,69}=0.05$ & 0.832 & $F_{1,69}=16.24$ & $\mathbf{0 . 0 0 0 1}$ & $F_{1,69}=21.67$ & $<\mathbf{0 . 0 0 0 1}$ & $F_{1,69}=0.33$ & 0.565 \\
Delay of maternal return & $F_{1,69}=3.81$ & 0.055 & $F_{1,69}<0.01$ & 0.976 & $F_{1,69}=0.46$ & 0.502 & $F_{1,69}=1.39$ & 0.242 \\
\hline
\end{tabular}

In these models, filial egg cannibalism was entered either as a continuous variable in the form of female weight gain or as a categorical variable in the form of cannibal versus noncannibal mothers. LR: likelihood ratio. Significant $P$ values are in bold. 
Table A1.Effects of female weight at egg laying, egg cannibalism and egg production on hatching success using a data set without females that had a hatching success of zero

\begin{tabular}{|c|c|c|c|c|}
\hline & \multicolumn{2}{|c|}{$\begin{array}{c}\text { Female weight gain used as a proxy } \\
\text { of egg cannibalism }\end{array}$} & \multicolumn{2}{|c|}{$\begin{array}{c}\text { Category of female cannibalism used } \\
\text { as a proxy of egg cannibalism }\end{array}$} \\
\hline & $\mathrm{LR}_{1}$ & $P$ & $\mathrm{LR}_{1}$ & $P$ \\
\hline Initial female weight & 5.63 & 0.018 & 4.44 & 0.351 \\
\hline Filial egg cannibalism (FEC) & 11.24 & 0.001 & 7.01 & 0.008 \\
\hline No. of first-clutch eggs (NE) & 0.64 & 0.425 & 1.27 & 0.260 \\
\hline $\mathrm{FEC} * \mathrm{NE}$ & 0.06 & 0.807 & 1.44 & 0.231 \\
\hline
\end{tabular}

In these models, filial egg cannibalism was entered either as a continuous variable in the form of female weight gain

or as a categorical variable in the form of cannibal versus noncannibal mothers. LR: likelihood ratio. Significant $P$ values are in bold. 


\section{FIGURES}
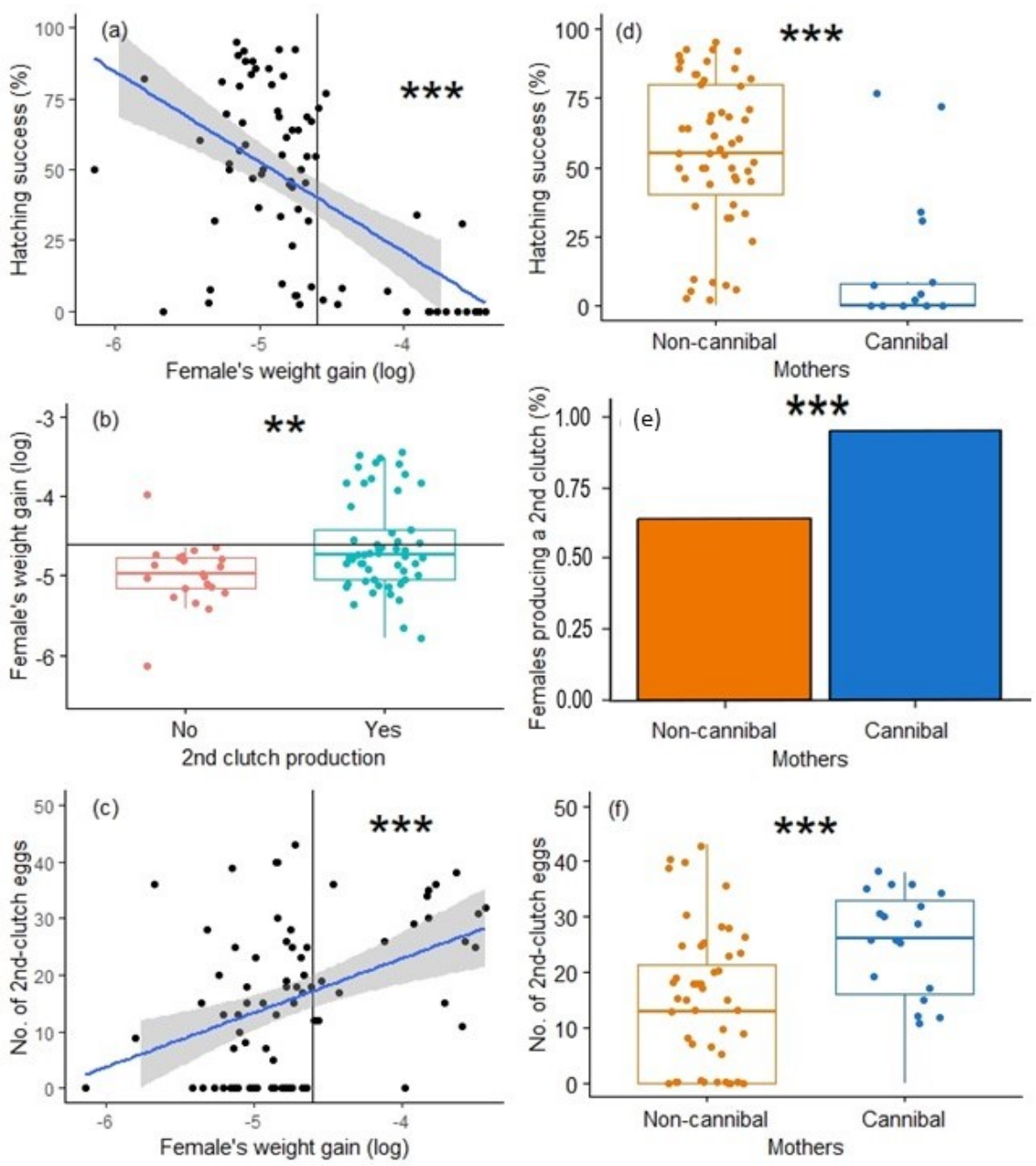

Figure 1. Associations between filial egg cannibalism and (a, d) egg hatching success, (b, e) likelihood of producing a second clutch and $(c, f)$ number of second-clutch eggs produced. (a, b, c) Quantitative proxy of filial egg cannibalism (i.e. female weight gain). (d, e, f) Qualitative proxy of egg cannibalism (cannibal versus noncannibal mothers). (a, c) Grey zones represent the standard error of each regression line. Vertical lines show the value corresponding to a null female weight gain, i.e. $\log (0.01)$ ( $\mathrm{b}, \mathrm{d}, \mathrm{f})$ Box plots depict median (bold bar) and interquartile range (light bar), with whiskers extending to 1.5 times the interquartile range and dots representing experimental values. $* * P<0.01 ; * * * P<0.001$. 

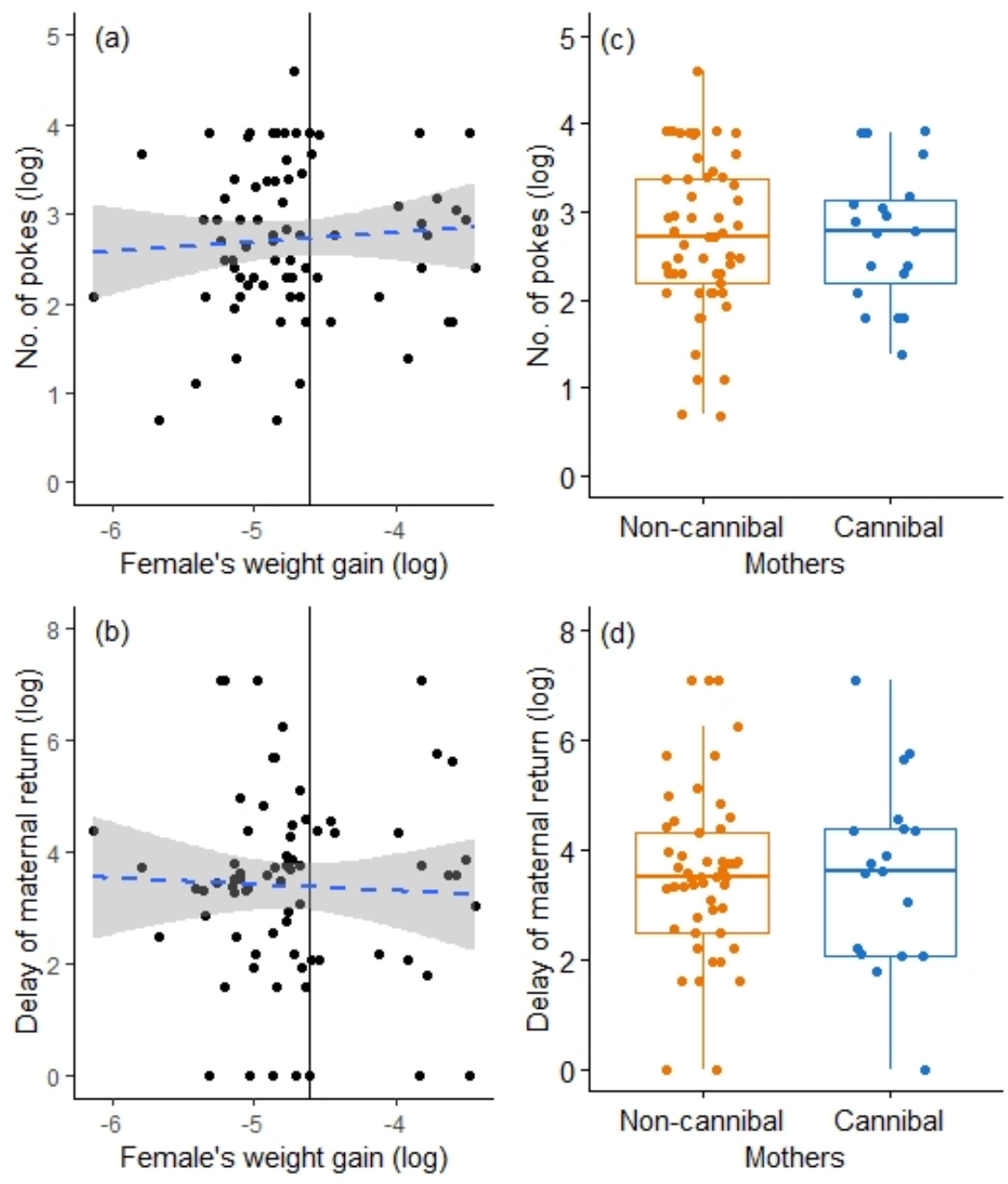

Figure 2. Association between filial egg cannibalism and two forms of maternal care: (a, c) clutch defence and (b, d) delay of maternal return (the delay after which females returned to their clutch after being chased away by a simulated predator attack, i.e. poking with a capillary). (a, b) Quantitative proxy of filial egg cannibalism (i.e. female weight gain). (c, d) Qualitative proxy of egg cannibalism (cannibal versus noncannibal mothers). (a, b) Grey zones represent the standard error of each regression line. Vertical lines show the value corresponding to a null female weight gain, i.e. $\log (0.01)$. (c, d) Box plots depict median (bold bar) and interquartile range (light bar), with whiskers extending to 1.5 times the interquartile range and dots representing experimental values. 

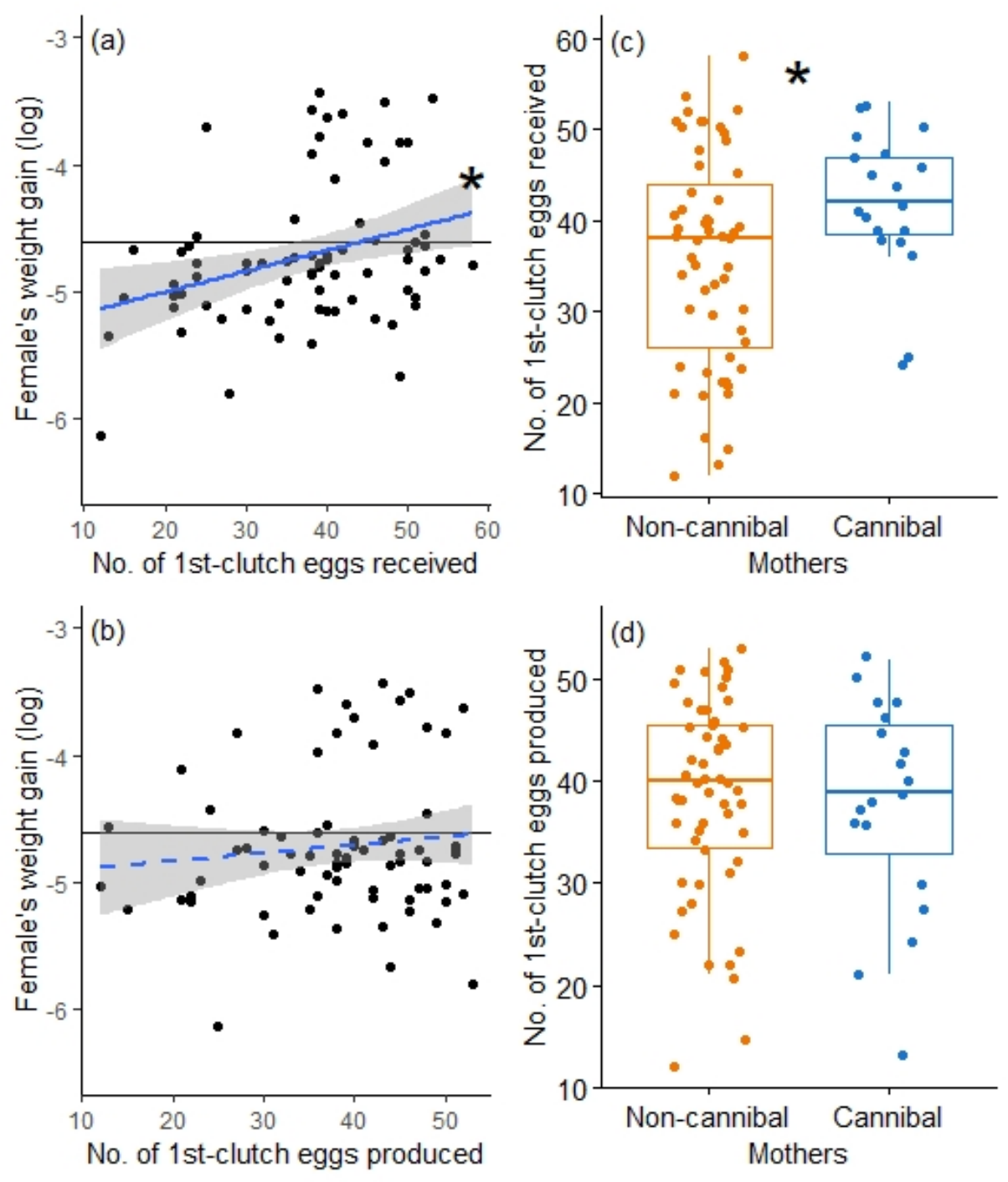

Figure 3. Association between filial egg cannibalism and the number of eggs either $(a, c)$ received or $(b, d)$ produced by the foster mothers. (a, b) Quantitative proxy of filial egg cannibalism (i.e. female weight gain). (c, d) Qualitative proxy of egg cannibalism (cannibal versus noncannibal mothers). ( $(a, b)$ Grey zones represent the standard error of each regression line. Vertical lines show the value corresponding to a null female weight gain, i.e. $\log (0.01)$. (c, d) Box plots depict median (bold bar) and interquartile range (light bar), with whiskers extending to 1.5 times the interquartile range and dots representing experimental values. $* P<0.05$. 


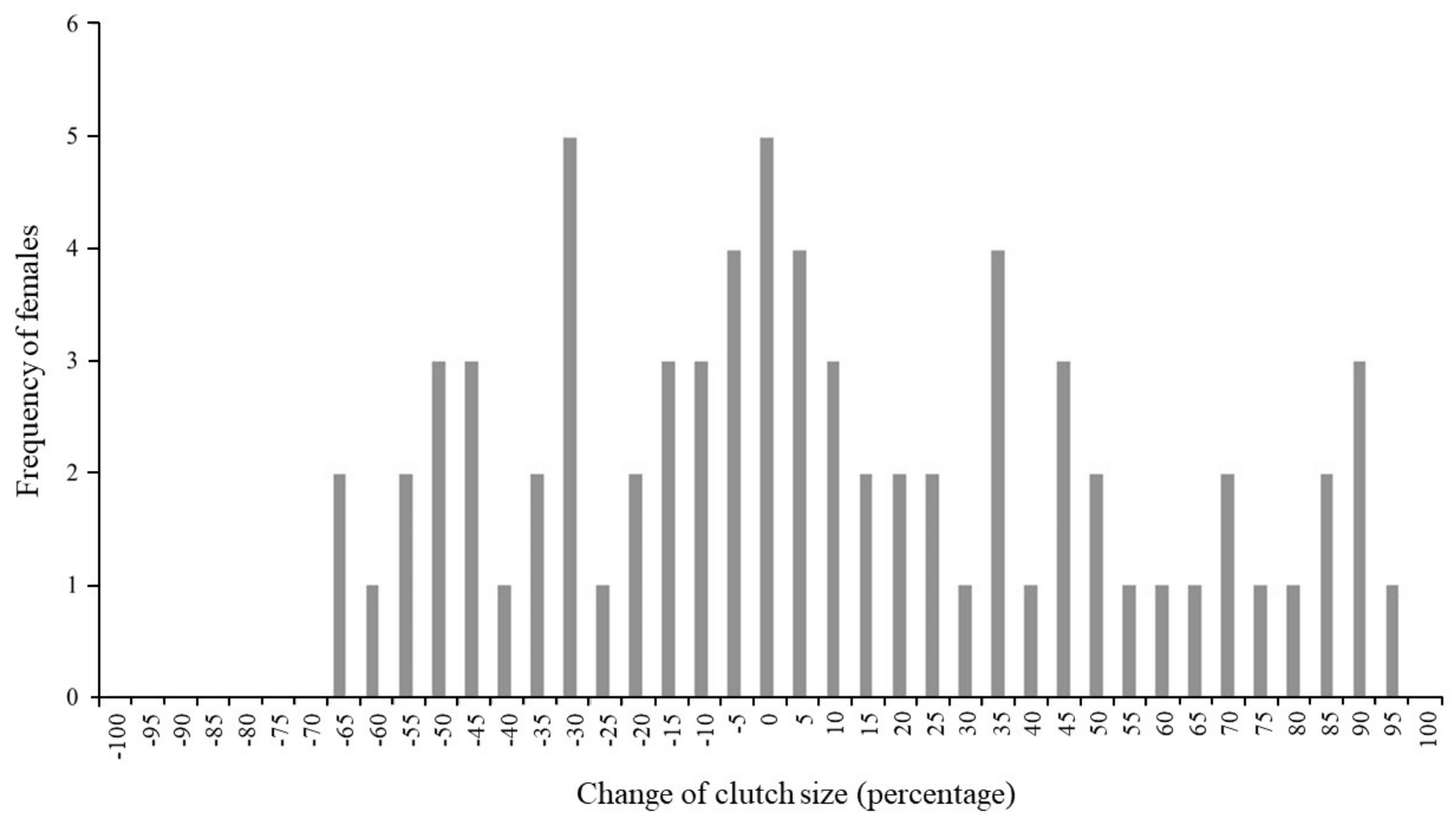

Figure A1. Number of females per change in clutch size [(number of eggs received - number of eggs produced)/number of eggs produced] when eggs were cross-fostered between females. 